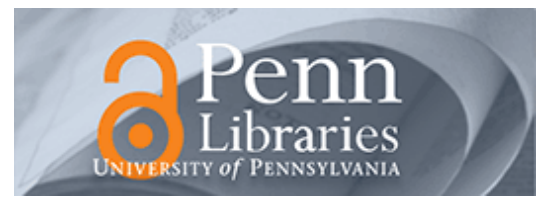

University of Pennsylvania

ScholarlyCommons

January 2004

\title{
From Good Student to Outcast: The Emergence of a Classroom Identity
}

Stanton Wortham

University of Pennsylvania, stanton.wortham@bc.edu

Follow this and additional works at: https://repository.upenn.edu/gse_pubs

\section{Recommended Citation}

Wortham, S. (2004). From Good Student to Outcast: The Emergence of a Classroom Identity . Retrieved from https://repository.upenn.edu/gse_pubs/49

Published as Ethos, Volume 32, Issue 1, 2004 @ 2004 by the Regents of the University of California/American Anthropological Association]. Copying and permissions notice: Authorization to copy this content beyond fair use (as specified in Sections 107 and 108 of the U.S. Copyright Law) for internal or personal use, or the internal or personal use of specific clients, is granted by the Regents of the University of California/on behalf of the American Anthropological Association for libraries and other users, provided that they are registered with and pay the specified fee via Rightslink ${ }^{\circledR}$ on [Caliber (http://caliber.ucpress.net/ ) /AnthroSource (http://www.anthrosource.net) or directly with the Copyright Clearance Center, (http://www.copyright.com ).

This paper is posted at ScholarlyCommons. https://repository.upenn.edu/gse_pubs/49

For more information, please contact repository@pobox.upenn.edu. 


\title{
From Good Student to Outcast: The Emergence of a Classroom Identity
}

\author{
Abstract \\ The process of social identification draws on heterogeneous resources from several levels of explanation. \\ This article illustrates how, by describing the identity development of one student across an academic \\ year in a ninth-grade classroom. Analyses of transcribed classroom conversations show teachers and \\ students drawing on multiple resources as this student goes from being identified as one of many good \\ students to being identified as a disruptive outcast. This case provides a counterexample to simple \\ theories of identity development that do not recognize the multiple, heterogeneous resources involved in \\ social identification.

\section{Comments} \\ Published as Ethos, Volume 32, Issue 1, 2004 @ 2004 by the Regents of the University of California/ \\ American Anthropological Association]. Copying and permissions notice: Authorization to copy this \\ content beyond fair use (as specified in Sections 107 and 108 of the U.S. Copyright Law) for internal or \\ personal use, or the internal or personal use of specific clients, is granted by the Regents of the University \\ of California/on behalf of the American Anthropological Association for libraries and other users, \\ provided that they are registered with and pay the specified fee via Rightslink $\circledast$ on [Caliber \\ (http://caliber.ucpress.net/ ) /AnthroSource (http://www.anthrosource.net) or directly with the Copyright \\ Clearance Center, (http://www.copyright.com ).
}




\title{
From Good Student to Outcast: The Emergence of a Classroom Identity
}

\section{STANTON WORTHAM}

\begin{abstract}
The process of social identification draws on heterogeneous resources from several levels of explanation. This article illustrates how, by describing the identity development of one student across an academic year in a ninth-grade classroom. Analyses of transcribed classroom conversations show teachers and students drawing on multiple resources as this student goes from being identified as one of many good students to being identified as a disruptive outcast. This case provides a counterexample to simple theories of identity development that do not recognize the multiple, heterogeneous resources involved in social identification.
\end{abstract}

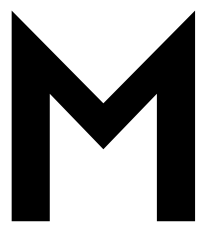

ost work on identity in classrooms studies the processes through which groups of students are treated in systematic ways. Some studies attend to individual students, but most often as examples of how their groups are systematically treated or as examples of how an individual can combine two types of identities. There has been much less attention to what Dorothy Holland and Jean Lave (2001) call "history in person." Individual identities exist only in social contexts, and any study of classroom identities must attend to social categories and processes. But individuals follow unique "trajectories of participation" across social contexts, sometimes in unexpected ways (Dreier 2003). We know much about how individual students follow typical trajectories of participation within and across classrooms. But we know less about how individuals' trajectories can deviate from the typical ones in complex ways. This article describes how students can develop unique individual

ETHOS, Vol. 32, Issue 2, pp. 164-187, ISSN 0091-2131, online ISSN 1548-1352. (C) 2004 by the American Anthropological Association. All rights reserved. Send requests for permission to reprint to: Rights and Permissions, University of California Press, Journals Division, 2000 Center Street, Suite 303, Berkeley, CA 94704-1223. 
identities within social context and how attention to individual trajectories of participation can illuminate both personal and sociohistorical processes.

An individual's identity depends on social categories and processes, as Mikhail Bakhtin (1981) and George Herbert Mead (1934) have described. The process of social identification, even when practiced privately by an individual, involves the use of social resources to construct self-understanding. But how do individuals end up on unique trajectories of social identification? Holland and Lave (2001) argue that both social and individual processes play a role. Neither the individual nor the society is prior. Both are in motion, and they codevelop. Individuals move along ontogenetic trajectories of identity, constrained by larger patterns but also potentially identifiable in various ways at any point. Social groups, institutions, and traditions-including those that carry categories of identity available to individuals-also move along extended, more slowly developing trajectories. When an individual comes consistently to be identified in one way, in an institutional context that also solidifies as individuals get identified, Holland and Lave (2001) describe it as the "thickening" of identity.

Given the various identities that any individual could enact in a given context, however, how do individuals come consistently to be identified as a recognizable type of person? Stable individual identities emerge when various actors draw on multiple resources to establish an emergent, provisionally stable identity in a given context. Over an academic year in a classroom, for example, students sometimes become recognizable types of people. Such local identities emerge as teachers and students draw on institutional resources, habitual classroom roles, the curriculum, and other resources to position students in recognizable ways.

This article describes the identity development of one student across an academic year in one ninth-grade classroom. It shows how she develops from being one of several good students to being an outcast in the classroom, as the teachers, other students, and she herself come consistently to position her this way. With ethnographic description of the ecology of the classroom as background, the paper traces classroom interactions through which this student becomes an outcast. Analyses of these interactions do not fully explain this student's social identity development. That would require more extensive data, across time and social settings. But the analyses do describe how her social identity in this classroom develops, and they illustrate how teachers and students use multiple resources to thicken this student's identity over the academic year. The case shows how an adequate account of identity development must acknowledge the multiple layers of resources that contribute to the process. 


\section{MULTIPLE RESOURCES FOR SOCIAL IDENTIFICATION}

One central concern of this special issue involves the relationship between "positioning" and "thickening." I would define positioning as an event of identification, in which a recognizable category of identity gets explicitly or implicitly applied to an individual in an event that takes place across seconds, minutes, or hours. As mentioned above, Holland and Lave (2001) define thickening as the increasing presupposability of an individual's identity over ontogenetic time, as the individual and others come increasingly to think of and position him or her as a recognizable kind of person. Positioning is context-specific and often unpredictable. As Harold Garfinkel (1967) and Erving Goffman (1976) have shown, individuals routinely get positioned in unexpected, sometimes nonnormative ways. But identities often thicken, such that we can unproblematically treat particular individuals as certain types of people. Both psychological and sociocultural stability often depend on stable, thickened identities. Among other things, this special issue explores how such stability gets accomplished in practice, given the indeterminacy inherent in events of positioning.

A general account of how identities thicken is beyond the scope of this article. A full account would have to explore an individual's experience, motivation, and cognition over time, as well as the categories and practices of identity available in both broad and local social groups. This article has a more modest aim: to describe the heterogeneous resources involved in the thickening of one student's social identity in a classroom over an academic year. This description does not suffice to establish one account of "positioning" and "thickening" as correct. But it does present a counterexample to accounts that privilege one or two types of psychosocial resources as primary to social identification. Many resources, drawn from diverse realms and complexly layered, can play a role even in relatively local, short-term social identification. We should be skeptical of accounts that claim to explain all social identification without attending to such complexity.

Urie Bronfenbrenner (1979), Michael Cole (1996) and Jay Lemke (2000) all describe how the resources for social identification come at several levels or "timescales." Each of them claims that accounts of social identity development must attend to resources at multiple levels-a claim that this paper supports empirically. A timescale is the spatiotemporal envelope within which a process happens. The emergence of capitalism, a process which in some respects has taken millennia, and in other respects centuries (cf. Postone 1993), occurs across a very long timescale. In contrast, individuals develop their capacities and live their lives at an ontogenetic timescale, across decades. Particular groups develop relationships 
and local habits, like those that emerge within a classroom over a year, at an intermediate timescale. And events take place at shorter timescales, taking minutes or hours. Processes and resources from many timescales generally contribute to the social identification of an individual. But there is no universal set of resources that constitutes social identification in all cases (Wortham in press). Instead, different configurations of resources contribute to the thickening of social identity in different cases. It would be empirically false to claim that some timescale, or some particular combination, is naturally basic to social identification.

The analyses below illustrate how one student struggles with and against her emerging identity in a classroom. The analyses show how intermediate timescale processes, like the development of categories within a particular classroom over several months, play an essential role in the thickening of this student's identity. These particular processes and resources are not naturally the right ones for studying all social identification and social life. The relevant processes and timescales will vary depending on the focal phenomenon being analyzed. Nor have I analyzed all timescales relevant to the social identification of this student in this classroom - to do so would require more space and more data. I do show that adequate analysis of social identification in this case must attend to how processes and resources from various timescales interconnect. I emphasize the intermediate timescale processes of teachers and students' months-long development of categories and identities, in order to show how "micro" and "macro" timescales by themselves will not suffice to explain social identification.

One resource for social identification is categories of identity drawn from the social context. As Bakhtin (1981) puts it, individuals and groups do not create unique categories de novo, but must instead "rent" categories from the society in order to make sense of themselves and others. These categories of identity often come packaged in larger models that show habitual characteristics, relationships, and events involving recognizable types of people. Such models have been described in cognitive psychology (e.g., Johnson-Laird 1983), in cultural anthropology (e.g., Holland and Eisenhart 1990; Lévi-Strauss 1960), and in cultural psychology (e.g., D'Andrade and Strauss 1992; Holland et al. 1998). An individual's identity thickens in part with reference to public models of identity.

As the case below shows, however, categories and models of identity do not jump from the sociohistorical to the ontogenetic timescale unchanged. Sociohistorical categories and models of identity get mediated through institutional and more local processes before they contribute to the thickening of an individual's identity. In the case below, for instance, the teachers and students draw categories and models of identity out of the curriculum and apply these to a particular student. The categories 
available to them have a particular form because the teachers (and textbook developers) have constructed curricular concepts in a certain way. Thus, the social identity that gets built with these categories has a specific form, because the categories are mediated through the textbook developers' selection and presentation of material, through the teachers' planning of their distinctive curriculum, and through classroom discussion that enacts curriculum in a particular way.

Teachers and students in this classroom also draw on models of identity specific to the pedagogical aims embraced by the school. These students are enrolled in a special program, one that follows the "Paideia" (Adler 1982) and "great books" (Great Books Foundation 1991) approach to teaching. Among other things, this approach urges teachers not to convey preestablished answers but, instead, to explore students' arguments. Teachers ask "essentially contestable" questions and invite students to take positions and make supporting arguments. In this context a student who dutifully repeats what the teacher has said is not considered successful, while a student who challenges the teacher and provides convincing arguments is considered successful. Students who boldly assert their own points of view, as we will see, can be categorized either as successful or as disruptive in this context, whereas they would likely be identified as disruptive in most classrooms.

The student described below develops from being assertive in the good sense to assertive in the bad sense, over several months. This transformation did not happen only because these categories of identity were available to characterize her. There were many other categories and models of identity potentially available that did not contribute to her thickening social identity, although the sociohistorical and local context might have allowed them. The students and teachers adopted and applied particular categories and models of identity as they positioned themselves in various classroom events across several months.

The focal student herself, both in how she acts and in how she describes herself, sometimes identifies as a disruptive adolescent who struggles against adults like the teachers. At other times, she tries to distance herself from this identity as a disruptive student and identify herself as assertive in a good sense. The teachers also contribute to this student's social identification. Early in the school year they identify her as just another of the good students, one who makes arguments and defends them. A few months into the year, however, they begin to identify her as a disruptive student, both by explicitly labeling her and by positioning her interactionally. Other students also contribute to both the positive and the negative identification, following the teacher's lead. Occasionally, however, as the analysis shows below, another student will join the focal student and defend her against the teachers. 
The student's identity thickens over time as various people, including the student herself, position her in mostly convergent ways across many classroom events. (As stated above, a full account of social identification would involve other psychological and social factors, but the consistent interactional positioning described here plays an important role.) The thickening of identity in this case depends on resources from several timescales: sociohistorical models of identity and conventions for classroom behavior; more local appropriations of these models and conventions, mediated through these teachers' curricular plans and pedagogícal expectations; classroom-specific categories and models of identity that develop over several months as these teachers and students interact with each other; contingent positioning that emerges in classroom events, as teachers and students act with and against each other to create coherent interactions. The thickening of identity will in every case depend on such a heterogeneous set of resources, but in different cases the specific resources relevant to social identification will often vary.

\section{Methods and Ethnographic Background}

Colleoni High ${ }^{1}$ was a large three-story brick building that occupied an entire city block. When it was built about half a century ago, Colleoni enrolled primarily Catholic children from Irish and Italian backgrounds. When this research was conducted, more than a decade ago, the neighborhood had become predominantly African American, together with growing populations of Latino and South Asian immigrants. The student body was ethnically mixed and mostly working class. The student population was 50 percent black, 25 percent Latino, 15 percent white, and 10 percent Asian. The faculty contained many whites, some blacks, and a few Hispanics.

I spent a total of 128 hours at Colleoni over two years, more than 100 of them in classes. Three-quarters of these classroom hours came in the final year, when I audiotaped most classes that I observed. Throughout my time at Colleoni I took field notes, I had many informal conversations with teachers after classes, and I conducted interviews with teachers, administrators, and students. I spent about 50 hours in one particular class across the final year. Fifteen of the 19 students in this ninth-grade class were black, and 14 were female. Most class sessions I observed were run by one male and one female teacher, both of them white.

Like many other schools in the city, Colleoni participated voluntarily in desegregation by offering a special educational program to students throughout the district. At Colleoni, the program was based on guidelines from The Paideia Proposal (Adler 1982) and An Introduction to Shared Inquiry (Great Books Foundation 1991). Parents and educators 
considered this program to be academically superior to most neighborhood schools, but not equivalent to the prestigious magnet programs. About one-quarter of the students at Colleoni participated in this special program. Many of these students did not live in the neighborhood, and some commuted over an hour each way.

Adler and the Great Books Foundation recommend that students discuss "genuine questions." That is, "seminar" discussions should involve students presenting and defending positions on complex questions, not simply parroting back the teacher's preferred answers. The two ninthgrade teachers I spent most time with, Mrs. Bailey and Mr. Smith, ran joint history/English classes twice a week, when they had 80-minute seminar discussions with their 19 students. The other three days a week each teacher ran more conventional didactic lessons for 40 minutes each. Increasingly over the year, they engaged students in rich discussions of complex texts-discussions in which students came to recognize issues of enduring human concern and to formulate their own arguments about these issues.

I made contact with Colleoni through the administrator who ran the special program. I told him I was interested in observing the program itself, as well as classroom language use. He selected certain teachers for me to talk to. I spoke with these teachers, received permission from them, and then began visiting their classrooms. I introduced myself to teachers as someone who had read a lot about classrooms in books, but who did not know much about them in practice. I tried to minimize any authority I brought with me from the university, by presenting myself as a newcomer to educational research who wanted to learn how teaching and learning happen in practice-which was an honest self-presentation. Nonetheless, teachers were initially uncomfortable with me in their classrooms. I received many sidelong ǵlances, as well as indirect requests for information on what I was doing and what I thought of them. Like the teachers, at first the students wondered who I was and what I was doing. After a few weeks, however, teachers and students most often ignored me during class. They clearly knew I was there, especially when I began audio recording. After a particularly bad joke someone would occasionally comment "and that was recorded for posterity." But after the first few weeks of recording, I noticed few differences between the classes I had observed without recording equipment and those I taped.

The analyses for this article focus on "participant examples," in which students themselves become characters in examples used to discuss the subject matter (Wortham 1994). As illustrated below, teachers and students often use such examples to draw categories of identity from the curriculum and apply them to students themselves (Wortham 2003). In analyzing the tapes and fieldnotes from Mr. Smith and Mrs. Bailey's class, I 
transcribed all participant examples and identified any implications they might have for students' social identities. The methods of discourse analysis, which identify types of cues that often serve as signs of identity, are described in Wortham (2001b). In addition, I have gone through all tapes and notes, looking for explicit statements about, and implicit positioning relevant to, the focal student's identity. The data analyses in the next section present instances from across the year in which this student gets socially identified, plus one typical, extended example that illustrates how teachers and students used multiple resources to position this student and thus reinforce her emerging local identity.

\section{TYISHA THE DISRUPTIVE OUTCAST}

From near the beginning of the year in Mrs. Bailey and Mr. Smith's class, teachers and most students presupposed that girls and boys have different social identities with respect to school. As Mrs. Bailey said explicitly one day, girls are easier for teachers to deal with, because they conform to school expectations, and they are also more likely to succeed in school and in adulthood. Boys are more difficult to deal with, because they resist school expectations, and they are less likely to succeed both in school and in later life. This expectation about identity draws on circulating sociohistorical patterns, like those that identify black male students as particularly concerned with respect and more likely to resist participation in school (Anderson 1999; Ferguson 2000) and those that identify adolescent boys as disdainful of school success (Newkirk 2002). But the gender difference was especially salient in this classroom, for two reasons. First, Mrs. Bailey believed what she said-she both explicitly and implicitly stated it throughout the year, and the girls took many opportunities to remind the boys about these alleged gender differences. Second, the boys tried to sit together in the back of the room, and all but one of them generally refused to participate, while many girls participated actively and dominated classroom discussions. For more evidence of this local gender difference, see Wortham (forthcoming).

\section{From Typical Girl to Disruptive Outcast}

At the beginning of the year, Tyisha fit this gender stereotype: She was an active, successful female student. She was engaged, offering her opinions on many subjects related to class discussion. Most of the students started the year trying to figure out and parrot back what the teachers wanted them to say. Because Tyisha rarely did this, but instead offered her own opinions, the teachers initially identified her as a student who made her own arguments. In a Paideia seminar this is desirable, so Tyisha 
was treated as a normal and even as a good student. This social identity drew both on locally robust models of gender identity and on locally robust models of Paideia or great books students.

The following segment comes from a class on October 9. ("T/B" stands for Mrs. Bailey; "FST" stands for an unidentified female student; "TYI" stands for Tyisha; transcription conventions are in the appendix).

T/B: okay, we've got women having babies. how does

40 TYI: it doesn't, to me.

T/B: it doesn't to you. how about you?

FST: maybe they think that that's supernatural.

T/B: that that's supernatural? having a baby is supernatural.

At line 40 Tyisha fails to give an answer the teacher is looking for. She also emphasizes her opinion, by adding the phrase "to me." But Mrs. Bailey does not evaluate Tyisha negatively. In fact, the teacher repeats Tyisha's utterance and goes on to ask for another student's opinion. Mrs. Bailey often asks several students in turn for their opinions on issues raised in the text, and here we see how Tyisha's tendency to offer her own opinions fits with the teacher's expectations. Especially early in the year the teachers often react positively to Tyisha's offering her own opinions, because they want other students to do the same.

Later in the October 9 class, Tyisha says something deliberately offtopic, apparently as a joke. In the following segment they are discussing bees, in order to understand a Chinese myth that compares humans to insects.

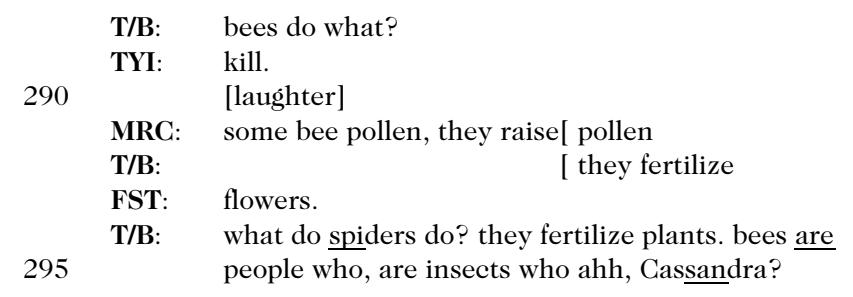

At line 290 several students treat Tyisha's comment as a joke, by laughing. It was a small joke, but apparently successful. Note that the teachers do not discipline Tyisha for this, as they would most likely have done later in the year. Mrs. Bailey simply ignores Tyisha's comment and continues with the discussion. Tyisha then reenters the conversation more constructively.

$\begin{array}{ll}\text { T/B: } & \text { how long do insects live? } \\ \text { CAN: } & \text { maybe ten days, about [ a week } \\ \text { MRC: } & \text { [ a week. } \\ \text { T/B: } & \text { a day, a couple of months, alright }\end{array}$


TYI: some of them a day because you know, if they bite you, they die.

T/B: okay some of them as soon- as soon as they, they, they put their stinger in it, they're dead. okay, now put that back to Pampu. why might the Chinese believe or feel that man comes from the earth as an insect. that man is similar to an insect?

At lines 322-23, Mrs. Bailey restates and thus ratifies Tyisha's comment as a useful contribution, one that allows Mrs. Bailey to articulate her analogy between the mortality of bees and the idea of humans as insects (at lines 323-326).

At the beginning of the year, then, the teachers positioned Tyisha as a normal or a good student. They appreciated her opinions, and they did not discipline her when she made jokes. After a month or two, however, several other students learned to offer arguments and give evidence as called for in a Paideia or great books classroom. At this point the teachers increasingly distinguished between Tyisha's comments-which they began to characterize as "opinions" offered without supporting evidence-and more successful students who gave better arguments. Tyisha's behavior had not changed much. But relative to the teachers' expectations and to other students' increasingly successful participation, it looked as if Tyisha was acting differently. In December and January, her social identity began to shift from that of a good student to one who inappropriately pushes her own opinion, who gives incorrect answers and who disrupts class by leading discussion off topic. Both teachers and other students began to treat her this way, drawing on a more traditional model of appropriate classroom behavior in which students do not disrupt the teacher's agenda.

Some evidence for this comes from the teachers' increasingly blunt evaluations of Tyisha. Right before the following segment (from January 18), Mrs. Bailey had just given an interpretation of a text from Aristotle that they had read. Aristotle is not saying that women are slaves to men, only that the relationship between a man and woman is partly analogous to the relationship between a master and a slave.

TYI: okay, when- um Sylvia was talking about the slave and the master, the master, okay, the slave, he uses his hands and stuff but- they won't give him a chance to use his- to teach him to read and stuff and the master know how, so he using his mind. why does he [ [4 unintelligible syllables]

T/B: [ okay, didn't- you 435 just missed the connection, the con- the thing is thatdo not look at this as saying that slaves are manual workers, slaves- women are slaves. look at these as four distinet relationships. 
Tyisha's reasoning wanders a bit from lines $428-433$, but she is apparently struggling with issues relevant to the academic discussion. Nonetheless, Mrs. Bailey interrupts to tell her that "you just missed the connection" (lines 434-435).

This incident alone might have reflected momentary impatience on the teacher's part, but the following evaluation follows immediately.

T/B: $\quad$ and in Greeks- in Greece, there certainly were slaves that used their mind. yeah?

445 FST: I'm talking about going back to what Tyisha said about how slaves that- well- if, okay if a master didn't teach the slaves how to read, how did they learn how to read? how did we know how to read and talk ourselves?

T/B: o[kay, you just missed-

450 TYI: [ right, thank you.

T/B: you just missed the point.

JAS: you missed the point. we're not compari[ng them.

TYI: [I know, but I'm talking about-

455 T/B: okay, look at this again, mental, manual workers, are mental workers

At line 445 an unidentified student refers back to the earlier comment by Tyisha, building on Tyisha's comment to ask a question. Normally these teachers encouraged students to refer to each other's comments, as a way of developing more complex arguments across the group. And at line 450 Tyisha explicitly thanks the other student for resuscitating her point and asking the question.

But Mrs. Bailey immediately jumps in (at lines 449 and 451) and returns to her earlier evaluation of Tyisha's point, with similar phrasing: "you just missed the point." The speed of Mrs. Bailey's intervention, and her blunt characterization of Tyisha's (and the second student's) point, is uncharacteristic for this class. These teachers want students to develop their own arguments, and they generally help students who are struggling to articulate something. But by January they have started to expect that Tyisha's points will not contribute to the conversation-that her comments are disruptive and not substantive. Note that another student (Jasmine) echoes Mrs. Bailey's evaluation of Tyisha at line 452. Other students, too, have come to presuppose that Tyisha's comments will lead the class off topic and are not worth pursuing. Jasmine also uses "we" in line 452, probably to distinguish Tyisha from the teachers and the other students. Tyisha did have one defender in this instance, the unidentified girl who sided with her at line 445 . We will see Jasmine herself side with Tyisha in the extended example below. Tyisha and others sometimes resist the change in her social identity, trying to retain her identity as a student who contributes productively to academic discussion, in the face 
of the teachers' and students' positioning her as academically incorrect and disruptive.

The split between Tyisha and students who contributed to class broadened over time, as Tyisha was increasingly identified as a student prone to give incorrect answers and lead the discussion off topic. The teachers continued to react quickly and harshly to many of her comments, presupposing that her contributions were intellectually unproductive and disruptive. The following segment, for instance, comes from January 25.

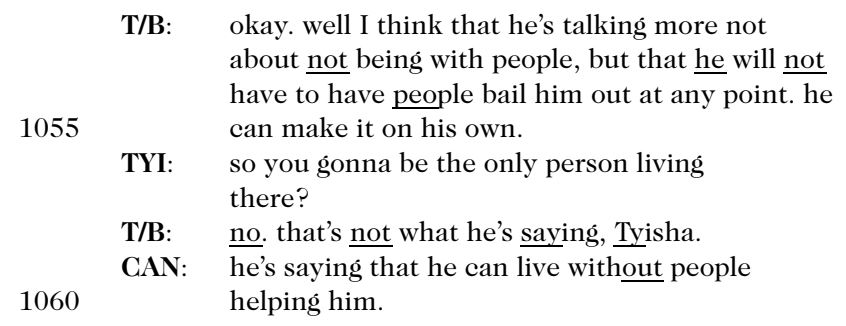

At lines 1052-1055, Mrs. Bailey is summarizing her interpretation of a point. Tyisha offers a gloss at lines 1056-1057, a gloss that misstates Mrs. Bailey's point, and the teacher reacts immediately by telling Tyisha she is wrong. This quick and blunt response contrasts with the teachers' habitual reaction to other students, and to Tyisha herself earlier in the year, when they would have explored her point or been more gentle in evaluating her response. Another student gives a more accurate gloss at lines 1059-1060 and the class ignores Tyisha and goes on discussing the point.

By February, Tyisha's identity as a disruptive outcast had thickened. It was then generally presupposable that she was disorganized, prone to offer comments that took the class off topic, and concerned with her own ideas more than with helping the group develop a coherent discussion. Thus Tyisha became an exception to the gender stereotype that teachers and students continued to presuppose. She was a girl who nonetheless was not a good student and was not likely to succeed. In the following segment, for example, from February 11, Mr. Smith explicitly characterizes Tyisha as a bad student who does not listen.

50 T/S: I will do a spot check, spot check your notebook. the notebook, and you better listen Tyisha, because you have a habit of never listening to me. Tyisha

TYI: I know what you're talking about[

T/S: [no.

55 TYI: you're talking about[ the notebook

T/S: [your ears are unfortunately

closed sometimes.

T/S: number five. who made the laws?

65 FST: the assembly. 


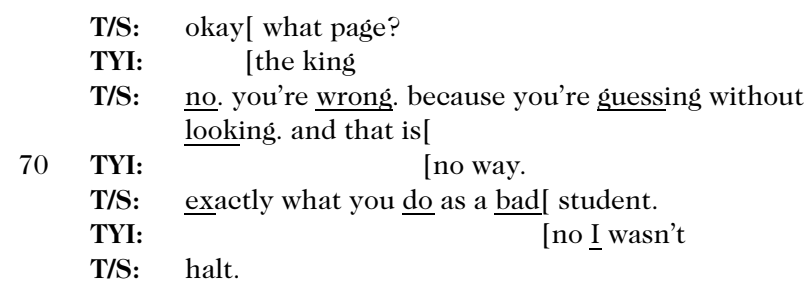

At line 52, Mr. Smith says that Tyisha never listens to him. And at line 71 he ealls her a bad student. Mr. Smith had a temper, and he sometimes made inappropriate comments like this about other students. But Tyisha was more likely to be the target, as teachers and students increasingly presupposed that she made inappropriate contributions and took the class off topic.

My data contain at least a dozen other telling examples, from December through May, of how Tyisha was explicitly identified as disruptive by the teachers and students. They accused her of not listening, of being wrong, and of making comments that led discussion off track. These comments collectively show that the teachers and students came to identify her differently than they did earlier in the year. From September through November she was just another student, and sometimes a good one, but by December and January she had become a disruptive student who made incorrect comments that derailed discussions. Instead of taking time to explore the reasoning behind her comments-and, it must be said, there was only sometimes defensible reasoning behind them-the teachers and other students quickly dismissed Tyisha and moved back to their own discussion.

\section{Tyisha the "courageous liar"}

Tyisha did not become a disruptive outcast solely through the teachers' treatment of her. She herself often embraced an oppositional identity. Sometimes she did this in ways that the teachers themselves identified as productive, when she challenged arguments made by the teachers and authors of the texts. Sometimes, however, at least from the teachers' perspective, she wasted class time while defending unreasonable positions and refusing to admit a mistake. She also made arguments and interrupted the teachers in apparently deliberate attempts to antagonize them. Occasionally, she explicitly described herself as opposing social norms and adults like the teachers.

So Tyisha's development from good student to disruptive outcast involved multiple resources. The teachers and some students drew categories of identity both from typical models of classroom behavior (e.g., students should not waste teachers' time by guessing out loud or by 
offering irrelevant opinions) and from more local Paideia-inspired models (e.g., students should collaborate with others to develop arǵuments, instead of pushing their own opinions). But, after initially resisting this identity during November and December, in January and February Tyisha sometimes positioned herself as a disruptive outcast. Her own actions thus contributed to her new social identity.

The curriculum provided another resource that students and teachers used to identify Tyisha. In January the class began discussing the relationship between individuals and society. In these discussions teachers and students often made analogies between the classroom itself and a society. To discuss Aristotle's arguments about how humans depend on their societies and contribute to a larger whole, for example, they might discuss how individual students contribute to class discussion. These analogies made available curricular categories that were used to identify students. For example, teachers and students came to use Aristotle's concept of an "outcast" to identify Tyisha. While discussing the class as a "society," in order to understand what Aristotle meant when he discussed social outcasts, Tyisha was identified as like the outcasts discussed by Aristotle. Because she refused to contribute constructively to the group discussion, preferring to disrupt the group activity, she could be identified using the category of outcast that they had developed in their discussion of Aristotle. Thus, teachers and students used the curricular category of "outcast" as a resource to make Tyisha's emerging identity more specific (see Wortham 2003, for an example).

This use of curricular categories to identify students like Tyisha most often happened in a particular type of speech event, "participant examples" (Wortham 1994). I have identified eight segments from classroom discussions (lasting on average about half an hour), from November through February, in which Tyisha becomes a participant example. Participant examples include, as a character in the example, at least one teacher or student who is participating in the classroom discussion. Such examples double the roles played by those teachers or students, because they become characters in the example as well as participants in the classroom discussion. This doubling of roles makes participant examples rich sites for socially salient interactional positioning (Wortham 1994, 2001a). Discussion of participants' hypothetical identities within the example can communicate things about the actual participants, as a sort of double entendre. Furthermore, it turns out that the content represented by a participant example and the interactional patterns enacted through that example can sometimes run parallel (Wortham 1994, 1997). That is, in discussing certain events as the content of an example, teachers and students sometimes enact analogous events in their classroom interaction. Examples involving such a parallel between representation and enactment use the 
same curricular categories both to discuss the curriculum and to identify students participating in the example, and, thus, they facilitate the use of curricular categories as a resource for social identification. Tyisha's identity certainly gets presupposed and reinforced in other classroom events, but I argue that these eight participant examples carry particular force because of the extended focus on her as a topic and because of the power that such examples can have (cf. Wortham 1994, 2001b). Each of the eight examples draws an analogy between an issue in the text and some actual or hypothetical characteristic of Tyisha-usually something about her as a person who acts for her own good without considering the good of the larǵer group.

The following example illustrates how a participant example can get enacted and how teachers and students use discussion of the curriculum to thicken Tyisha's identity as a disruptive outcast. This discussion occurred on January 18, while the class was exploring Aristotle's definition of courage as articulated in his Politics. At this point in the discussion Mrs. Bailey had asked whether a person could courageously obey as well as courageously resist. She suggested that one could obey courageously, and she gave brief examples like overcoming anxiety to give a presentation in class. Tyisha then volunteered her own participant example, supposedly to support Mrs. Bailey's point, saying "Mrs. Bailey, I think I have one."

As it turns out, however, Tyisha's example does not illustrate Mrs. Bailey's point and it leads the class off track. Given that Tyisha laughs while giving the example, and that she defends her example with increasingly outrageous claims, it may well be that she intended to make a joke and take the class off topic. She did similar things at other times during the year. Tyisha introduces her example as follows.

TYI: okay, I(hhh)- I had a friend. and she was like, sneaking out with a boy, and she lied and said that she was going with her friends. (hh) a(h)nd she told me, if my mother call, to tell her she was at the zoo with her friend Stacey. now that took her courage to te(h) 11 me.

FST: $\quad \overline{(h h h)[}$

TYI: [ and it took e(hh)oura(h)ge for me to tell her mother that.

275 FST: $\overline{\mathrm{mh}}$

T/B: did it take courage for[ her to tell her mother tha[t?

FST: [ no [I don't think so

T/B: why would that

280 TYI: [ yeah it took courage to tell my mother

FST: [3 unintelligible syllables]

MRC: I don't think it took courage.

Tyisha gives her example at lines 267-271, and then at lines 273-274 she claims that it took courage for her to lie to her friend's mother. 
Because they are discussing Aristotle's definition of courage, this might be a relevant example to explore-even though it does not illustrate the concept of "courage through obedience" that Mrs. Bailey had asked for.

But the example presents some interactional problems for the teachers, as Tyisha may have intended. Because the example involves immoral behavior (at least from an adult's point of view), if Tyisha's behavior was in fact courageous then the teachers would have to acknowledge her courage while condemning her behavior. Tyisha might be using this discussion of subject matter to put the teachers in an awkward position, or at least to slip illicit topics into an academic discussion in such a way that she cannot be sanctioned for it. She is both adopting and reveling in an oppositional identity, as an adolescent who helps her friend get away with illicit dates and who can also manage to talk about this in an academic discussionperhaps even in such a way that her oppositional behavior gets classified as courageous. Thus, she gives an example of herself being oppositional in relation to her friend's mother, and she herself acts oppositional in the class by giving this as an example.

By laughing several times while she gives her example, Tyisha (at lines 267, 269, 271 and 273) and another student (at line 272) seem to support this interpretation of her example as partly a joke or, perhaps, an attempt to trap the teachers between illicit topics and academic content. At line 276, Mrs. Bailey implies that Tyisha's behavior was not courageous, and a student agrees with her at lines 277-278. Tyisha interrupts Mrs. Bailey's next comment, to restate that she was in fact courageous. Maurice then sides with the teacher at line 283, denying that Tyisha's lie took courage. So Mrs. Bailey's initial reaction to Tyisha's challenge is to deny that Tyisha was courageous in lying to her friend's mother.

Mr. Smith, however, gives Tyisha another opportunity to make her case in the next segment. He interrupts Mrs. Bailey's attempt to change the topic, saying (at lines 287-288) "let her finish." Then he asks:

295 T/S: then, which is courage?

T/B: $\quad$ shhh

FST: [so you gonna sit there and lie to[her face

T/S: [lying [to lie or to tell the

truth be[cause you

300 FST: [to tell the truth

T/S: knew that she was wrong.

CAN: cause its wrong

FST: tell the truth. tell the truth

TYI: both of them

305 JAS: both of them take courage [ to me

TYI:

[both of them take

cou [rage, you all wrong

[ explain how both. 
Mr. Smith calls for Tyisha to elaborate her example, perhaps hoping that she will provide something more for them to work with in interpreting Aristotle's account of courage. He also explicitly describes Tyisha as "lying," for the first time (at line 298). When Tyisha gave the example, she used the term tell to describe her speech act (lines 270,273), although she said her friend was "sneaking out" and "lied" to her mother (lines 268).

In Mr. Smith's response it becomes clear that he was not really siding with Tyisha. At lines 295 and 298-299, Mr. Smith asks whether it was really courageous to lie, or whether it would in fact have been more courageous to tell her friend's mother the truth. At lines 300,302, and 303, other students side with Mr. Smith, claiming that lying is wrong and that telling the truth would have been more courageous. But at line 304 Tyisha claims that both lying and telling the truth could have been courageous, and at line 305 Jasmine agrees with her. Tyisha ends with a characteristic utterance at line 307- "you all wrong." Note how she is separating herself off from the rest of the class and defending an unpopular position. This separation is not only enacted in her argument against the teachers and other students in the classroom but also presupposed in the content of the example. By describing herself as someone who breaks moral rules, which the teachers and many of the students adhere to, Tyisha further marginalizes herself from other members of the group.

Mr. Smith then asks Tyisha to explain how both lying and telling the truth could be courageous. So she continues.

TYI: because $(\mathrm{hhhh}[\mathrm{h})$

310 FST: [ because

T/S: let her

TYI: if I lyin'- If I'm sittin' here lying in another person mother face, that took courag(h)e. [ and if I'm

T/S: [ why?

315 TYI: telling her because you don't-

FST: lies.

T/S: have you never lied to your mother?

FST: hnuh

TYI: no- not- not to no one else's momma, no.

320 T/S: have you ever lied to a teacher who is a mother?

FST: uh(hhh)

TYI: that's different.

FST: aw man.

STS: [2 seconds of laughter]

325 TYI: that's very different um- I mean that's different. I'm always over there visiting this friend and her mother, might have had trus- trust in me and I come over and tell her this big, bold faced lie.

From lines 309-315, Tyisha reiterates her claim that lying to her friend's mother took courage. Mr. Smith then takes control of the conversation, 
asking her questions at lines 314, 317, and 320. Mr. Smith's question at line 320 brings the example closer to students' and teachers' real identities in the classroom, when he asks whether Tyisha has "ever lied to a teacher who is a mother." Mrs. Bailey is in fact the mother of a teenage girl. She has mentioned this in class, so students know it. Mr. Smith's question highlights the interactional tension that Tyisha's example raises. Tyisha is proud of the fact that she lied to her friend's mother, even though Mrs. Bailey and other adults would clearly identify with the friend's mother and consider this wrong. Mr. Smith thus may be implying that Tyisha opposes Mrs. Bailey and people like her.

Tyisha revels in this oppositional identity, as illustrated in the sequence of increasingly colorful terms that she uses to describe her lie. As noted above, she started by using the verb "tell" to describe what she said to her friend's mother (at line 270). Mr. Smith reframed this as a "lie" at line 298, and opposed such lying to "telling the truth" (line 298). Another student spiced up the characterization: "so you gonna sit there and lie to her face" (line 297). Tyisha herself embraced this characterization at lines 312-313: "I'm sitting here lying in another person mother face." And she ends up with: "her mother might have had trust in me and I come over and tell her this big bold-faced lie" (lines 326-328). Far from euphemizing what she did, Tyisha embraces the oppositional character of her action and proudly flaunts social norms. This clearly opposes her to Mrs. Bailey, who might be worrying about her own daughter's friends doing the same thing to her.

In addition to embracing an oppositional identity, Tyisha has embedded her assertion of oppositional identity within an academic discussion about Aristotle's concept of "courage." This hijacking of the discussion itself constitutes an oppositional act. Mr. Smith nonetheless continues to pursue the discussion for its academic potential. Perhaps he thinks that he can win the argument about whether Tyisha was in fact courageous. Or perhaps he recognizes that her argument has some merit. It is at least arǵuable that one can sin courageously. In the following segment Tyisha and Jasmine pursue this argument.

T/S: did you feel courage or did you feel guilt?

330 TYI: I felt both of them [2 unintelligible syllables]

T/S: courage to be guilty? [quizzical intonation contour, mid-low-mid]

TYI: (hhh) nah, but it took courage to do[ that.

JAS: $\quad$ it do take

335

courage to be guilty.

STS: [1 second of laughter]

TYI: I know. like we goin' to [ steal something. it took

T/S: [ you should be guilty

TYI: courage for me to go sneakin out of the store, right? 


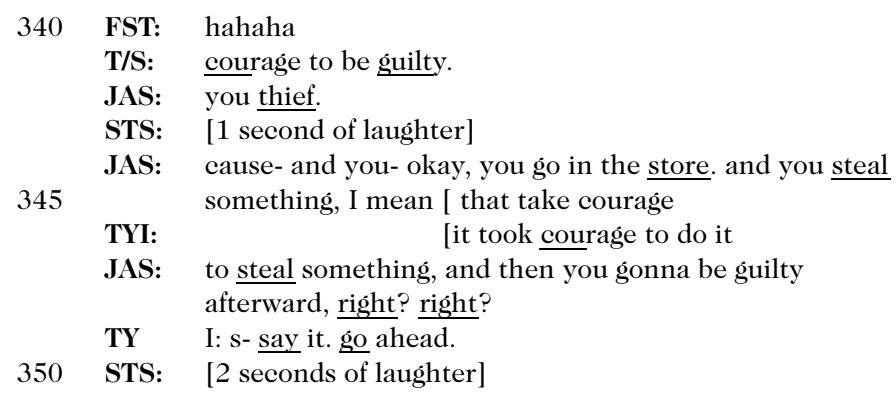

At line 329, Mr. Smith returns to the question of whether Tyisha felt courage or guilt while lying. Tyisha claims she felt both. Mr. Smith then seems to be making fun of her argument with a "quizzical" intonation contour. Students laugh a bit after his remark. After Tyisha reiterates that her lie was courageous at line 333, Jasmine apparently makes fun of Tyisha at lines 334-335, saying "it do take courage to be guilty." Students laugh at the joke.

It is ambiguous here, however, whether the other students are laughing at Tyisha or with Tyisha. If my reading has been correct, Tyisha has all along intended for her example to be at least partly a joke. So it may be that she has succeeded at getting other students to laugh. Jasmine's comment at lines 334-335, however, seems to follow up on Mr. Smith's quizzical comment and to make fun of Tyisha. Tyisha responds with a second example, one involving more serious transgressions than the first, at lines 337-339. She may be trying to build on the success of her first example, which managed both to make a joke and to condone oppositional behavior. But Mr. Smith's echoes Jasmine's tease at line 341, and then Jasmine herself laughingly calls Tyisha a thief.

It appears for a moment as if everyone is laughing at Tyisha, but then Jasmine sides with her in the argument against Mr. Smith. At lines 344348, Jasmine agrees with Tyisha that moral transgressions like stealing take courage (see also Jasmine's own earlier comment at line 305). Tyisha echoes this at line 346. It is relevant here that Jasmine is the most verbally skilled of the students. She won the schoolwide student talent competition that year, and she regularly had the class rolling with laughter. She is entertaining here, judging from other students' reactions, but her comments also contribute to the academic argument. Stealing does seem to take courage. By joining Tyisha's side of the argument, Jasmine may change Tyisha's social identity-from an oppositional student disrupting classroom conversation to a good student offering a plausible argument. In January, other students most often join the teachers in identifying Tyisha as disruptive. But Jasmine's behavior here illustrates how Tyisha and other students will occasionally reassert her old identity as a good 
student. Tyisha's identity as a disruptive outcast does emerge in January, but it is also strugggled over.

In several subsequent lines, not included here, a student objects that stealing is wrong while Tyisha and Jasmine defend their claim that stealing can be both courageous and guilt inducing. Then another student claims that stealing is wrong and brings the discussion back to the concept of courage.

385

LIN: I don't think that's courage to go and steal a candy bar

[ because courage- right

MST: [ it's stupid

LIN: cause courage, the virtue of courage, what we read of courage was to do something- something good, not to do something and go and do something [evil.

TYI:

[that's not

true

FST:

right

[yeah that's

TYI: courage is not just doing something good.

[students talking at once]

TYI: if I go[ shoot you in the head

T/B: [ shhhhhh

[students arguing]

T/B: $\quad$ ahh, if we can- if we can talk about courage as being

something good, the virtue of courage, and go back to that definition, and I know you never bought into it, but the rest of us seem to be, using this as a definition, so therefore, we'd ask you to kind of go along with it.

FST: okay.

405 T/B: the idea of courage, was not just doing things you're afraid to do, but doing things that- overcoming your fear for a good reason. Linda?

LIN: I was saying what Tyisha said, if you go shoot somebody in the head, you gonna call that courage? or you is gonna call that stupid?

While Linda disagrees with Tyisha and Jasmine's claim that stealing requires courage (at line 384), one of the male students slips in a characterization of stealing: "it's stupid" (line 386). One might infer that people like Tyisha who practice and defend such behavior are also stupid. Linda then makes an even more evaluative comment about stealing and other moral transgressions: they are "evil" (line 389). This casts Tyisha and Jasmine as defending something unforǵivable.

Tyisha continues to argue that one can courageously commit immoral acts. But at line 396 she chooses an example that does not seem suited to an academic discussion. "If I go shoot you in the head" is provocative, because of the second person pronoun and because shooting someone is even more unethical than stealing and lying. By escalating the immorality 
of the topic, Tyisha seems to be pushing the discussion toward what Goffman (1974) called "flooding out"-bursting out of its character as an academic discussion and becoming simply an occasion for laughter or confrontation. Tyisha compounds this by speaking in the first and second person, imagining herself shooting some of the other students and, perhaps, the teachers.

Mrs. Bailey's reaction at lines 399-403 frames Tyisha's comments as an attempt to disrupt the classroom discussion. Mrs. Bailey could have said: "that's an interesting argument Tyisha, but how can an act be both virtuous and immoral at once? Would Aristotle have agreed with that?" Instead, she skillfully frames Tyisha's comment as moving against the will of the rest of the class, without baldly asserting her own authority. She starts at lines 399-401 by establishing her version of the contested issue as a "definition." Tyisha has argued that immoral acts can require courage, and this seems a defensible position. But Mrs. Bailey asserts that courage is something good, by definition. Tyisha and Jasmine "never bought into" this definition, "but the rest of us" did. Tyisha and Jasmine, then, get positioned outside the teachers' and others students' group, as people who adopt idiosyncratic definitions and, thus, hinder group discussion. Mrs. Bailey acknowledges their dissent and asks them to go along instead of imposing her will. It would violate her pedagogical philosophy to tell students what to think. But in fact she has characterized Tyisha and Jasmine as the sort of people who refuse to accept agreed-on definitions and who thus disrupt the productive work that the rest of the class is pursuing.

In this discussion of lying, stealing, and shooting, then, Tyisha both embraces an oppositional identity and also skillfully manages to insert discussion of these topics into discussion of the curriculum. The teachers and other students follow up and identify Tyisha as morally suspect and as an outcast. Their discussion excludes Tyisha from the group of teachers and other students in two ways. First, Tyisha gets (willingly) characterized as the sort of person who would baldly lie to a friend's mother, unlike the rest of them. Second, she positions herself in the discussion, and gets positioned, as a student who makes jokes, takes the class off topic, and refuses to accept generally agreed-on definitions. Her identity as an outcast and a disruptive student thus thickens further-at Tyisha's own initiative, but also with the help of the teachers and students.

\section{GONGLUSION}

The teachers and students discussed several participant examples like this one during the academic year, in which Tyisha was both described 
and interactionally positioned as a disruptive outcast (cf. Wortham 2003; in press). These examples, together with explicit characterizations of her as disruptive, helped teachers and students draw on multiple resources to identify Tyisha. From September through November, she was a normal student. But in December, January, and February she increasingly became a disruptive one and an outcast from the group of cooperative students. This social identification emerged in contrast to the local expectation that girls are more cooperative and more likely to succeed, and in this respect Tyisha's identity was idiosyncratic.

Teachers and students used more enduring, familiar social categories to identify Tyisha. The concept of a disruptive student presupposes common models of appropriate classroom behavior and of teachers' authority. The category of "loud black girls" also circulates more widely (Fordham 1996), and one might argue that Tyisha is being identified with this category. But an account in terms of more prevalent, longer timescale categories like this would be incomplete. All the students identified as cooperative, intelligent, and academically promising in this classroom were also black girls. Tyisha, in particular, was identified as disruptive because of more local, shorter timescale processes and actions. As we have seen, for instance, the category of "social outcast" became available through these teachers' local curriculum. Teachers and students applied this category to Tyisha, especially through participant examples. Furthermore, students engaged in complex acts that facilitated and struggled against Tyisha's emerging identity. Tyisha herself sometimes embraced her identity as an outcast. Students like Jasmine sometimes reinforced this identity, but sometimes they identified Tyisha as a good student or in other conflicting ways. Tyisha's trajectory of identification across the year, then, is an intermediate timescale phenomenon that must be explored in practice, not simply derived from sociohistorical patterns.

The thickening of identity happens across a trajectory of events as certain categories of identity come to identify an individual. Longer timescale, widely circulating categories and models are essential to social identification, but only as they are contextualized within local settings and particular events. Local settings like a classroom develop versions of more widely circulating models of identity, and participants in these settings come to presuppose those models in their events of identification. Individuals in those settings move along (sometimes) idiosyncratic trajectories that draw on both sociohistorical and local categories of identity in unique ways. An adequate analysis of social identification, then, must attend to available sociohistorical categories and models of identity, to the particular local versions of these that emerge in a given setting, to the trajectories of individuals who get identified over time with respect to local categories and models, and to the contingent events in which categories and models 
of identity get contextualized and acts of social identification happen. Different configurations of these resources will be crucial to social identifications in different cases, and we must attend to multiple resources and multiple timescales if we hope to explain identity development in practice.

STANTON WORTHAM is a linguistic anthropologist of education who serves as Professor and Associate Dean for Academic Affairs at the University of Pennsylvania Graduate School of Education.

\section{NOTES}

1. All names are pseudonyms. Other details have been changed to disguise the identity of subjects. Administrators, teachers, parents, and students gave permission for this study. Data were collected more than a decade ago.

\section{REFERENGES GITED}

Adler, Mortimer

1982 The Paideia Proposal. New York: Macmillan.

Anderson, Elijah

1999 Code of the Street. New York: W. W. Norton.

Bakhtin, Mikhail

1981[1935] Discourse in the Novel. C. Emerson and M. Holquist, trans. In The Dialogic Imagination. Mikhail Bahktin, ed. Pp. 259-422. Austin: University of Texas Press.

Bronfenbrenner, Urie

1979 Ecology of Human Development. Cambridge, MA: Harvard University Press.

Cole, Michael

1996 Cultural Psychology. Cambridge, MA: Harvard University Press.

D'Andrade, Roy, and Claudia Strauss

1992 Human Motives and Cultural Models. New York: Cambridge University Press.

Dreier, Ole

2003 Learning in Personal Trajectories of Participation. In Theoretical Psychology: Critical Contributions. Niamh Stevenson, H. Lorraine Radtke, René Jorna, and Henderikus Stam, eds. Pp. 20-29. Toronto: Captus Press.

Ferguson, Ann 2000 Bad Boys. Ann Arbor: University of Michigan Press.

Fordham, Signithia 1996 Blacked Out. Chicago: University of Chicago Press.

Garfinkel, Harold 1967 Studies in Ethnomethodology. New York: Prentice Hall.

Goffman, Erving

1974 Frame Analysis. New York: Harper and Row.

1976 Replies and Responses. Language in Society 5:257-313.

Great Books Foundation

1991 An Introduction to Shared Inquiry. 2nd edition. Chicago: Great Books Foundation.

Holland, Dorothy, and Margaret Eisenhart 1990 Educated in Romance. Chicago: University of Chicago Press. 
Holland, Dorothy, William Lachicotte Jr., Debra Skinner, and Carole Cain

1998 Identity and Agency in Cultural Worlds. Cambridge, MA: Harvard University Press.

Holland, Dorothy, and Jean Lave

2001 History in Person. Santa Fe, NM: SAR Press.

Johnson-Laird, Philip

1983 Mental Models. Cambridge, MA: Harvard University Press.

Lemke, Jay

2000 Across the Scales of Time. Mind, Culture, and Activity 7:273-290.

Lévi-Strauss, Claude

1960 The Savage Mind. Chicago: University of Chicago Press.

Mead, George

1934 Mind, Self, and Society from the Standpoint of a Social Behaviorist. Chicago: University of Chicago Press.

Newkirk, Thomas

2002 Misreading Masculinity. Portsmouth, NH: Heinemann.

Postone, Moishe

1993 Time, Labor and Social Domination. New York: Cambridge University Press.

Wortham, Stanton

1994 Acting Out Participant Examples in the Classroom. Philadelphia: John Benjamins.

1997 Denotationally Cued Interactional Events: A Special Case. Semiotica 114:295-317.

2001a Interactionally Situated Cognition. Cognitive Science 25:13-42.

2001b Narratives in Action. New York: Teachers College Press.

2003 Curriculum as a Resource for the Development of Social Identity. Sociology of Education 76:229-247.

In press Learning Identity. New York: Cambridge University Press.

\section{APPENDIX: TRANSERIPTION CONVENTIONS}

'-' abrupt breaks or stops

'?' rising intonation

'? falling intonation

', (underline) stress

(1.0) silences, timed to the nearest second

'[' indicates simultaneous talk by two speakers, with one utterance represented on top of the other and the moment of overlap marked by left brackets

'[... ]' transcriber comment

', pause or breath without marked intonation

'(hh)' laughter breaking into words while speaking. 